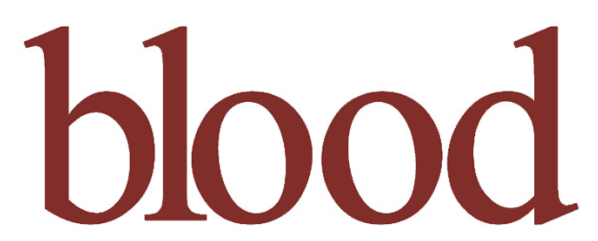

2008 112: $1720-1729$

Prepublished online Jun 17, 2008;

doi:10.1182/blood-2007-09-112748

\title{
Overexpression of delta-like 4 induces arterialization and attenuates vessel formation in developing mouse embryos
}

Alexandre Trindade, S. Ram Kumar, Jeffrey S. Scehnet, Luis Lopes-da-Costa, Jorg Becker, Weidong Jiang, Ren Liu, Parkash S. Gill and Antonio Duarte

Updated information and services can be found at:

http://bloodjournal.hematologylibrary.org/cgi/content/full/112/5/1720

Articles on similar topics may be found in the following Blood collections:

Hemostasis, Thrombosis, and Vascular Biology (2496 articles)

Information about reproducing this article in parts or in its entirety may be found online at:

http://bloodjournal.hematologylibrary.org/misc/rights.dtl\#repub_requests

Information about ordering reprints may be found online at:

http://bloodjournal.hematologylibrary.org/misc/rights.dtl\#reprints

Information about subscriptions and ASH membership may be found online at:

http://bloodjournal.hematologylibrary.org/subscriptions/index.dtl

Blood (print ISSN 0006-4971, online ISSN 1528-0020), is published semimonthly by the American Society of Hematology, 1900 M St, NW, Suite 200, Washington DC 20036.

Copyright 2007 by The American Society of Hematology; all rights reserved.

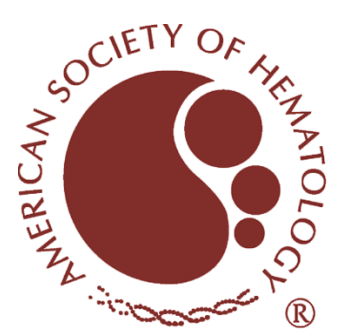




\title{
Overexpression of delta-like 4 induces arterialization and attenuates vessel formation in developing mouse embryos
}

\author{
Alexandre Trindade, ${ }^{1,2}$ S. Ram Kumar, ${ }^{3,4}$ Jeffrey S. Scehnet, ${ }^{3}$ Luis Lopes-da-Costa, ${ }^{1}$ Jorg Becker, ${ }^{2}$ Weidong Jiang, ${ }^{5}$ \\ Ren Liu, ${ }^{5}$ Parkash S. Gill, 3,6 and Antonio Duarte ${ }^{1,2}$ \\ ${ }^{1}$ Centro de Informatica do Instituto Superior de Agronomia (CIISA), Lisbon Technical University, Lisbon, Portugal; ${ }^{2}$ Instituto Gulbenkian de Ciência, Oeiras, \\ Portugal; Departments of ${ }^{3}$ Pathology and ${ }^{4}$ Surgery, University of Southern California Keck School of Medicine, Los Angeles; ${ }^{5}$ Vasgene Therapeutics, \\ Los Angeles, CA; and ${ }^{6}$ Department of Medicine, University of Southern California Keck School of Medicine, Los Angeles
}

\begin{abstract}
The importance of Notch signaling pathway in the regulation of vascular development and angiogenesis is suggested by the expression of Notch receptors and ligands in vascular endothelial cells (ECs) and the observed vascular phenotypes in mutants of Notch receptors or ligands, especially DII4. DLL4 is specifically expressed in arterial ECs during development, and haploinsufficiency is embryonically lethal in mice. To address the role of DII4 in vascular development, we produced $\mathrm{mDII4}$ conditionally
\end{abstract}

overexpressed transgenic mice that were crossed with constitutive recombinase cre lines. Double transgenic embryos displayed grossly enlarged dorsal aortae (DA) and died before embryonic day 10.5 (E10.5), showing a variable degree of premature arteriovenous fusion. Veins displayed ectopic expression of arterial markers. Other defects included reduced vascular sprouting, EC proliferation, and migration. $\mathrm{mDI} / 4$ overexpression also inhibited VEGF signaling and increased fibronectin accumulation around the vessels. In vitro and in vivo studies of DLL4-FL (DII4-full-length) in ECs recapitulate many of the $\mathrm{mDI} / 4$ transgenics findings, including decreased tube formation, reduced vascular branching, fewer vessels, increased pericyte recruitment, and increased fibronectin expression. These results establish the role of DII4 in arterial identity determination, and regulation of angiogenesis subject to dose and location. (Blood. 2008;112:1720-1729)

\section{Introduction}

Arterial versus venous differentiation has long been thought to be mainly dependent on physical factors such as blood pressure and oxygen concentration. Recently, however, the identification of several genes that are specifically expressed in arterial or venous endothelial cells (ECs) well before the onset of circulation seems to indicate an important role for genetic determination of ECs in the primary differentiation events between arteries and veins. Among these genes are Eph-B4, specifically expressed in venous ECs ${ }^{1-3}$ and Ephrin-B2,1,3,4 Notch1, ${ }^{5}$ Notch $4^{6}$ and Dll4 ${ }^{7}$, among others, which are specifically expressed in arterial ECs.

Dll4 is the only Notch ligand known to have an expression pattern similar to Notch1 and Notch4 in the vascular system, being likewise restricted to the arterial endothelium. Mutation studies in zebrafish have shown that Notch homologues are the earliest genes expressed in an endothelial arterial specific fashion and regulate arterial and venous endothelial differentiation downstream of vascular endothelial growth factor (Vegf) and sonic-hedgehog $(S h h)$ and upstream of the ephrin pathway. ${ }^{8}$ There is growing evidence, in both zebrafish and mouse, that Notch function is essential in the establishment of the arterial endothelial cell fate. ${ }^{8-10}$ In this context, the ligand Dll4, given its arterial specific expression pattern and striking loss-of-function phenotype ${ }^{10}$ appears to play a pivotal role.

In the present study we investigated the role of Dll4 in mammalian vascular development by producing and characterizing murine gain-offunction mutants. To achieve generalized overexpression of $m D l l 4$, we produced conditional transgenic mouse lines, ZEG-Dll4, which when crossed with a constitutive cre line, CAG-Cre mice, ${ }^{11}$ express the native form of Dll4 under the control of the chick beta actin promoter and cytomegalovirus (CMV) enhancer. Whole-body mDll4 gain-of-function causes a profound phenotype in the developing vasculature, enhancing the arterial phenotype, fusion of large arteries and veins, enlarged arteries with excess fibronectin accumulation, and decreased vessel branching. A second transgenic line of endothelial cell specific Dll4 expression resulted in similar phenotype. Dll4 dose and location are critical for proper vessel formation, as either gain- or loss-of-function leads to profound vascular defects. Dll4 overexpression was also studied using in vitro and in vivo angiogenesis models recapitulating the findings in mutant mouse, which are reversed by the administration of a soluble form of Dll4.

\section{Methods}

\section{Generation of conditional $m D I I 4$ gain-of-function mice}

The study, project number CVT49766, was approved by the Faculty of Veterinary Medicine of Lisbon Ethics and Animal Welfare Committee. The mouse Dll4 cDNA was cloned into the pZ/EG transgenic vector (Figure 1A), ${ }^{12}$ a generous gift of Dr Corrine Lobe (Sunny Brook Health Science Centre, Toronto, ON), which contains a CMV enhancer/chick beta-actin promoter to drive strong constitutive expression of downstream coding sequences, along with 2 reporters, floxed beta-geo, 3x polyA and IRESGFP. The $m D l l 4$ cDNA was inserted downstream of the floxed beta-geo $3 \mathrm{x}$ polyA. Therefore, the transgenic expression of beta-geo signals the
Submitted September 14, 2007; accepted April 27, 2008. Prepublished online as Blood First Edition paper, June 17, 2008; DOI 10.1182/blood-2007-09-112748.
The publication costs of this article were defrayed in part by page charge payment. Therefore, and solely to indicate this fact, this article is hereby marked "advertisement" in accordance with 18 USC section 1734. 
Figure 1. mDIl4 overexpression causes major defects in the developing vascular system. (A) pZ/EG$\mathrm{mDII} 4$ transgenesis vector and result of Cre recombination. (B) LacZ staining of a ZEG-DII4 embryo at embryonic day 8.0 (E8.0). (C) EGFP expression in the double transgenic (DT) embryos at E8.5. (D) Haemorrhaging in the DT embryos at E9.0. Whole-mount PECAM1 immunostaining of E9.0 DT (E) and control (F) embryos. (F) DT embryo at E9.0 showing a hypertrophied dorsal aorta (red arrow), ramified ACV (green arrow), and an unbranched vascular plexus in the head region (blue arrow), relative to the control embryo (E). PECAM1 immunostaining of vitelline membranes from $\mathrm{WT}(\mathrm{G})$ and DT embryos $(H)$ show a blockage in the angiogenic remodeling of the vitelline vasculature of mutant embryos. (I,J) Serial sections of an E9.5 WT embryo demonstrating the region where the ACV (green arrow) connects to the sinus venosus (blue arrow; K-M) Serial sections of a E9.5 DT embryo (anterior-posterior) showing a fusion between the aorta (red arrow) and the ACV (green arrow) just before its connection to the sinus venosus (blue arrow). In panel $\mathrm{K}$ the ACV consists of a plexus of small capillaries (green arrow) that join to form a single vessel with a large lumen just before its fusion with the dorsal aorta (M). Microangiography with India Ink injection confirmed the existence of functional connections between the DA and the ACV of DT embryos (O), with ink flowing directly from the aortae (red arrow) to the sinus venosus (blue arrow), in contrast to the regular flow of the control embryos (N). Endothelial-specific overexpression of $\mathrm{mDll4}$ (DII4e) causes the same vascular defects as observed in DT embryos. (P) Immunofluorescence with anti-PECAM1 and anti-DII4 antibodies on WT embryo at E9.5. Immunofluorescence with anti-PECAM1 and anti-D\|l4 antibodies on DT embryo $(\mathrm{Q}, \mathrm{R})$ and D\|4e embryos at E9.5 (S,T), confirming that Dll4 is ubiquitously expressed in DT embryos and that it is panendothelial in DIl4e embryos, while WT embryos show only DII4 expression on the dorsal aortae (DA).
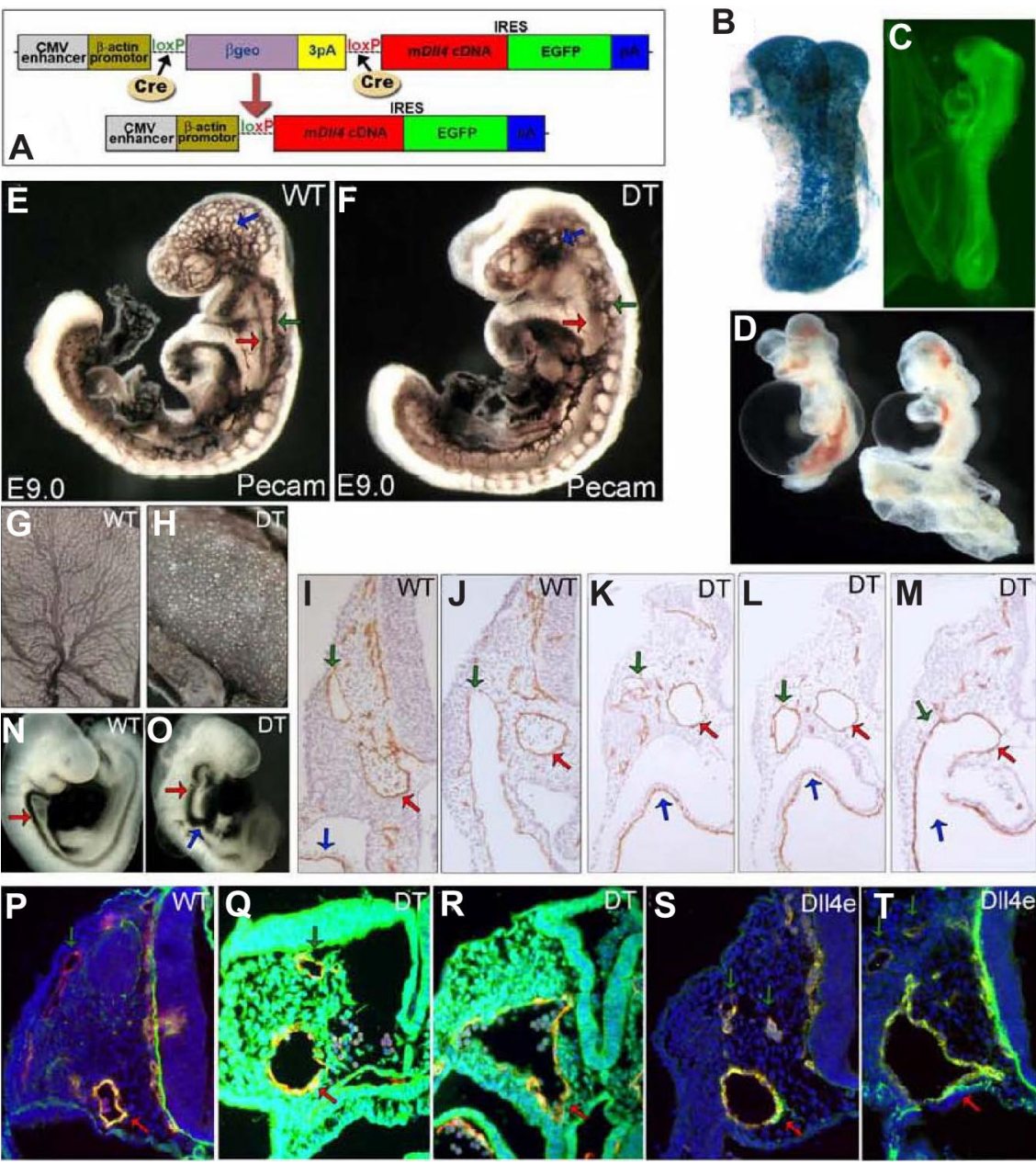

presence of the nonrecombined vector, whereas D114 and EGFP coexpression occurs on cre recombination. The vector was linearized with SfiI and BsaI and electroporated into R1 ES cells, transgenic clones were selected by incubation for 7 days in G418 containing media, aggregated with CD1 morulae and transferred into pseudo-pregnant CD1 females. Chimeric males were crossed with $\mathrm{CD} 1$ females and the agouti progeny was screened for germ line transmission of the transgene based on lacZ staining analysis of tail biopsy samples. Founder lines were characterized for embryonic lac $Z$ expression and those 2 with the strongest and most widespread expression were selected. Both lines displayed identical phenotypes when crossed with a constitutive chicken beta-actin cre (CAG-cre) transgenic mouse line. ${ }^{11}$ The $\mathrm{TetO}_{7}$-Dll4 transgenic construct was produced by cloning the mouse Dll4 cDNA into $\mathrm{p}\left(\mathrm{tetO}_{7}\right)$-CMV-bGH, ${ }^{13}$ a generous gift of Dr J. A. Whitsett (Cincinnati Childrens Hospital Medical Center, Cincinnati, OH). This construct was used in pronuclear microinjection to generate Dll4 conditional overexpression transgenics. Two different founders were obtained, displaying identical phenotypes when crossed with the tie2-rtTA-M2 transgenic line, a kind gift of Dr Urban Deutsch (Theodor Kocher Institute, Berne, Switzerland). Transgene expression induction was achieved by administration of doxycycline at $2 \mathrm{mg} / \mathrm{mL}$ in drinking water, with $4 \%$ sucrose, to pregnant females from E5.5 until the day of sacrifice. Animal studies were performed with approval from the institutional ethics committee.

\section{In situ hybridization and immunohistochemistry}

Whole-mount immunohistochemistry and lac Z staining was carried out by standard techniques. ${ }^{13}$ Antibodies were from Pharmingen (San Jose, CA; PECAM1/CD31) and (Sigma-Aldrich, St Louis, MO; SMA, fibronectin, and laminin). Digoxigenin-labeled RNA probes were transcribed from linearized templates, and in situ hybridization of cryosections was carried out as previously described. ${ }^{15}$ Probe sizes were as follows: EphrinB2, 700 bp; Eph-B4, 1466 bp; Flk1, 800 bp; Connexin37, 978bp; Notchl, 2168 bp; Heyl, 2215 bp.

Tissues were processed using standard methods. ${ }^{13}$ Sections were incubated with primary antibody overnight at $4^{\circ} \mathrm{C}$ and appropriate secondary antibody for 1 hour at room temperature. Antibody binding was localized with $\mathrm{ABC}$ staining kit from Vector Laboratories and peroxidase activity detected using diaminobenzidine substrate solution (Vector Laboratories, Burlingame, CA). The positive staining area was estimated using ImageJ and analyzed by Student $t$ test.

Fluorescent immunostaining was performed in a similar fashion. Appropriate fluorescein-conjugated secondary antibodies (Sigma-Aldrich) were used and nuclei were counterstained with 4', 6-diamidino-2-phenylindole dihydrochloride hydrate (DAPI; Molecular Probes, Eugene, OR). Images were obtained using an Olympus AX70 fluorescence microscope and Spot version 2.2.2 (Diagnostic Instruments, Sterling Heights, MI) digital imaging system

\section{In vivo proliferation assay}

Pregnant females were injected with $100 \mu \mathrm{g}$ BrdU per gram of live weight 2 hours before being humanely euthanized. Frozen sections were stained first with PECAM1/CD31 antibody, followed by antibodies against BrdU (SigmaAldrich), as previously described. ${ }^{16}$ Appropriate fluorescent secondary antibodies (Molecular Probes) were used and sections were counterstained with DAPI.

\section{Microangiography}

Ink injections were carried out in E9.0 embryos. Briefly, embryos were dissected in phosphate-buffered saline (PBS)-Tween $(0.1 \%)$ and immediately injected in the outflow tract of the heart with India ink diluted in PBS-Tween to 20\%, using glass micropipettes. Embryos were photographed directly. 


\section{Fluorescence-activated cell sorting purification of embryonic ECs and RNA preparation}

Nine to 12 somite control and double transgenic (DT) embryos were dissected free of extraembryonic membranes, digested in $0.1 \%$ Collagenase III (Worthington, Lakewood, NJ), and resuspended in cold 10\% FCS in HBSS. The cells were then blocked in 5\% rat serum and stained with allophycocyanin-labeled anti-PECAM1/CD31 antibody (Pharmingen) at 1:400 dilution. Viable cells were gated by their forward and side scatter characteristics, and gates were set to sort cell population positive for GFP and PECAM1/CD31 in double transgenic embryos, or only PECAM1/ CD31 positive in control embryos. Total RNA was extracted from both cell populations using the RNeasy MiniKit (Qiagen, Valencia, CA).

\section{Cell culture}

Healthy human umbilical vein endothelial cells (HUVECs) were obtained from Cambrex (Walkersville, MD) and maintained in EGM2-supplemented medium (Invitrogen, Carlsbad, CA). For all experiments, HUVECs were used at passages 4 or below. The 293 cell line was obtained from ATCC (Manassas, VA) and cultured under recommended conditions.

\section{DIl4 construct, transfection, cell sorting, and analysis}

Full-length human Dll4 gene was cloned by polymerase chain reaction (PCR) amplification from human cDNA (Clontech, Mountain View, CA) made from fetal lung tissue (amino acid residues 1-685) was expressed from pcDNA3.1 expression vector (Invitrogen) as previously described. ${ }^{17}$ Typically, HUVECs were transiently transfected with full-length D114 or vector alone. For sorting transfected cells, the MACSelect 4.1 selection kit (Miltenyi Biotech, Auburn, CA) was used as per manufacturer's instructions and previously described. ${ }^{17}$ Selection efficiency was confirmed by immunostaining using Dl14 monoclonal antibody. Cell proliferation assay and apoptosis assays were performed as previously described. ${ }^{17,18}$

\section{Endothelial cell tube formation assay}

Matrigel $(250 \mu \mathrm{L}$; BD Biosciences, Palo Alto, CA) was placed in each well of 24-well plate and allowed to polymerize as described. ${ }^{17}$ HUVECs in EGM2 medium were plated at a concentration of $10^{4}$ cells/well with test material at various concentrations in triplicates, and pictures were taken at various time points using a Bioquant Image Analysis system (Nashville, $\mathrm{TN})$. Length of cords formed and number of junctions was measured using ImageJ software (National Institutes of Health [NIH], Bethesda, MD). Experiments were repeated twice. ${ }^{19}$

\section{Murine Matrigel plug angiogenesis assay}

In vivo angiogenesis was assayed using the Matrigel plug assay as previously described. ${ }^{17}$ Matrigel $\left.(8.13 \mathrm{mg} / \mathrm{mL})\right)$ was mixed with test compounds at $4{ }^{\circ} \mathrm{C}$ and $0.5 \mathrm{~mL}$ was injected into the abdominal subcutaneous tissue of female Balb/C nu/nu mice (5 mice per group). Plugs were recovered on day 6 and processed for immunohistochemical analysis. To study the effect of full-length DLL4, $10^{6} 293 \mathrm{~T}$ transfected (vector alone or full-length DLL4) and sorted cells were placed in VEGF containing Matrigel for plug assays. Vascular identity of the infiltrating cells was established with PECAM/CD31 immunostaining. The experiment was repeated 3 times. The vascularized area in each section was calculated using ImageJ (NIH).

\section{Quantitative transcriptional analysis}

Real-time PCR analysis was performed on sorted ECs from wild-type (WT) and DT embryos or from 2 separate samples obtained from whole embryo lysates of WT and DT embryos. Gene expression was normalized to $\beta$-actin. For in vitro studies total RNA extracted from HUVECs transfected with vector and full-length Dll4 for reverse transcription (RT)-PCR with specific primers for Dll4, GAPDH, ß-actin, Notch1, Notch4, VEGFR2, Hey1, Hey2, Hes1, Hes2, fibronectin, laminin, PDGF, and PDGFRB as previously described. ${ }^{17}$ Primer pairs used in this study are available on request.

\section{Results}

\section{$m D I 14$ overexpression caused embryonic death at around E9.0 to E9.5}

Two founder mouse lines were generated using the following constructs (Figure 1A) that displayed strong and ubiquitous expression of lacZ (Figure 1B). Both of these lines produced a similar phenotype when crossed with the CAG-Cre mouse line, and one of these lines, referred to as Z/EG-Dll4 from here on, was used for further studies. Crossing Z/EG-Dll4 with endothelial-specific Cre lines, like Tie2-Cre, ${ }^{20}$ Tie1$\mathrm{Cre}^{21}$ or Flk1-Cre, ${ }^{22}$ produced no detectable embryonic vascular phenotype. Analysis of GFP expression, as a reporter of effective recombination by Cre, revealed that at E9.0 only $12 \%$ of ECs were GFP-positive (Figure S1B,C, available on the Blood website; see the Supplemental Materials link at the top of the online article). Alternatively, crossing Z/EG-Dl14 with CAG-cre led to in utero death of DT embryos $(n=46)$. The DT embryos dissected at E8.0 to E9.5 constitutively expressed GFP (Figure 1C), which indicated that cre recombination of the Z/EG-Dll4 conditional vector was occurring in all cells of the embryo, eliminating $\beta$ geo expression by excision of the floxed cassette and allowing coexpression of Dll4 and GFP, through an IRES element. By E9.0 these DT embryos displayed extensive hemorrhaging throughout the body, and pericardial effusion, along with failure to close the neural tube in the cephalic region (Figure 1D). No live DT embryos were recovered after E10.5 (data not shown; $\mathrm{n}=34$ ).

\section{$m D I I 4$ overexpressing embryos displayed vascular defects}

Whole-mount PECAM/CD31 immunostaining of E9.0 DT embryos revealed grossly dilated DA, ramification of the anterior cardinal vein (ACV), dilated heart and pericardium (Figure 1E,F). Vitelline vasculature of DT embryos did not remodel from the honeycomb shaped primary vascular plexus which persisted until the death of the embryo (Figure 1G,H). PECAM1/CD31 immunostaining of cross-sections of the DT $m D l l 4$ overexpression embryos showed fusion between the ACV and the DA leading to the formation of a bypass circulation from the DA to the sinus venosus region of the heart (Figure $1 \mathrm{~K}-\mathrm{M}$ ). The ACV appeared branched in most of the trunk (Figure $1 \mathrm{~K}$ ), and progressing to single luminal vein (Figure 1L) just before fusing with the dorsal aorta and the sinus venosus (Figure $1 \mathrm{M}$ ). India ink microangiography showed short circuit of perfusion between outflow and inflow tracts of the heart resulting from proximal fusion of arterial and venous compartments leading to reduced blood flow to the rest of the embryo (Figure 1N,O).

\section{Cardiovascular phenotype caused by endothelial-specific $m D I I 4$ overexpression is identical to that caused by ubiquitous mDII4 overexpression}

As the analysis of endothelial-specific overexpression was revealed to be impossible with the ZEG-Dll4 mouse line, we decided to produce a different conditional Dll4-overexpressing transgenic mouse line. This was intended to determine whether the observed phenotypic changes were a specific consequence of endothelial Dll4 overexpression or the outcome of generalized overexpression of $\mathrm{Dll} 4$. The $\mathrm{TetO}_{7}-\mathrm{Dll} 4$ mouse lines were crossed with Tie2-rtTA-M2 mice and DT embryos were analyzed at E8.5-E9.5. Induction started at 5.5 days postcoitus (dpc), 2 days earlier than the start of endogenous Dll4 expression, to allow for doxycycline saturation of the embryos to be achieved slightly earlier than the start of endogenous D114 expression. D114 immunostaining at 

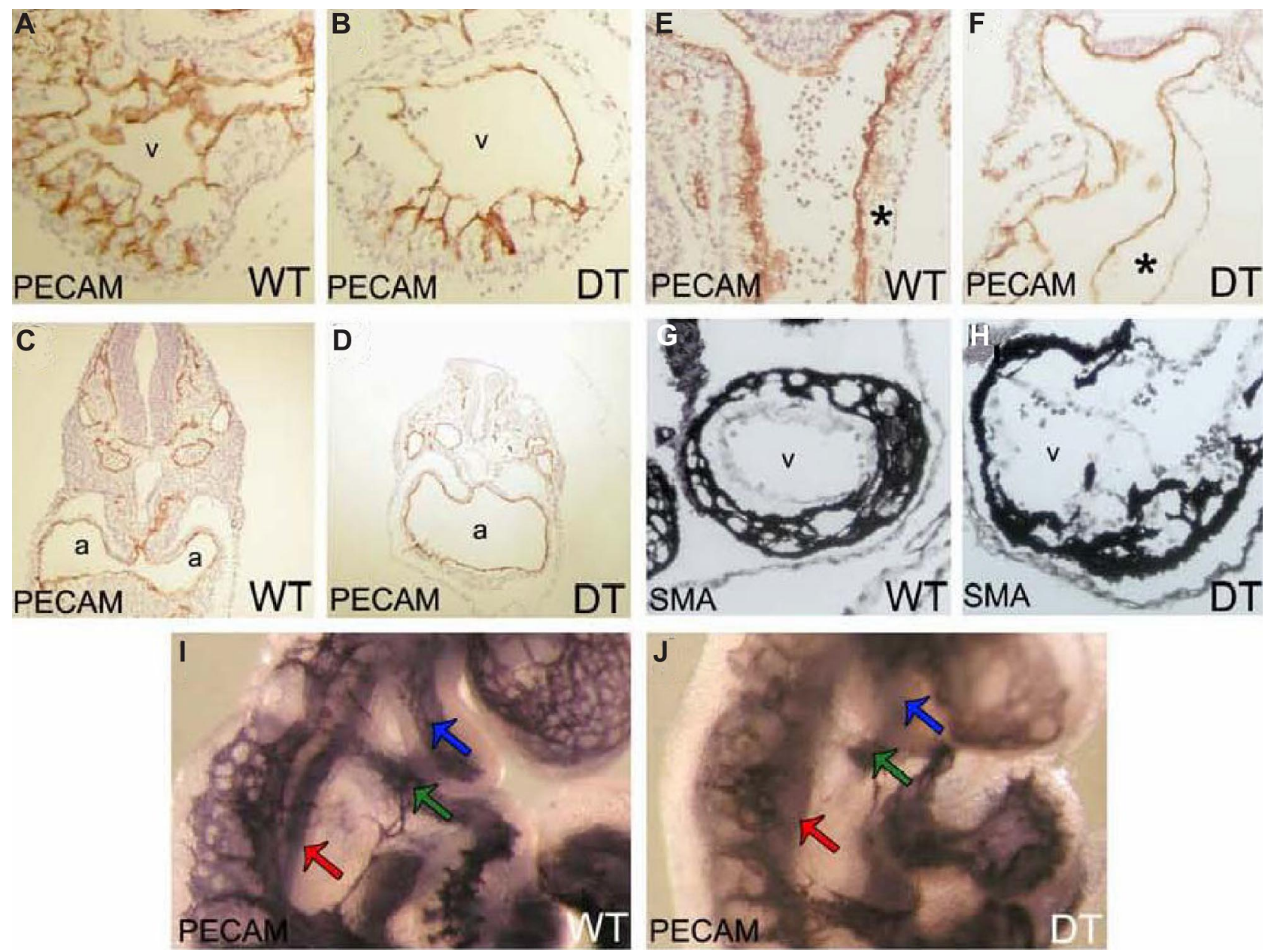

Figure 2. mDII4 overexpression causes morphogenetic defects in the developing heart. PECAM1 immunostaining of cryosections from E9.5 WT and DT embryos (A) WT heart ventricle (v) showing normal trabeculation. (B) DT heart ventricle (v) revealing reduced trabeculation. (C) WT heart atria (a). (D) DT heart atria (a) revealing gross hypertrophy. (E) Outflow tract of heart from WT embryo. (F) Outflow tract of heart from DT embryo, showing acellularization of the outflow tract cushions (*). SMA immunostaining of cryosections from E9.5 WT and DT embryos $(\mathrm{G})$ heart ventricle $(\mathrm{v})$ of WT embryo. $(\mathrm{H})$ Heart ventricle $(\mathrm{v})$ of DT embryo showing aggregation of cardiomyocites at the periphery of the ventricle and irregular distribution of cardiomyocites through the trabeculations, relative to WT. Whole-mount PECAM1 immunostaining of E9.0 WT and DT embryos. (I) WT embryo imaged at the heart level, showing normal arteries at the first (green arrow) and second branchial arches (blue arrow; DA, red arrow). (J) DT embryo imaged at the heart level, showing the presence of a fully formed artery at the first branchial arch (blue arrow) but only a very reduced or nonexistent artery at the second branchial arch (green arrow; DA, red arrow).

E9.0 showed marked endothelial-specific overexpression of $\mathrm{mDll4}$ (Figure S1F,G). The endothelial-specific $m D l l 4$ overexpressing embryos were growth-retarded and died at E10.5, exhibiting the same vascular defects as the DT embryos (Figure 1S,T).

\section{mDII4 overexpression alters cardiac morphogenesis}

Cardiac defects in DT embryos can be characterized by reduced myocardial trabeculation in the ventricles (Figure 2A,B), atrial distention (Figure 2C,D), and absence of cells within the outflow tract cushions (Figure 2E,F). In DT embryos, cardiomyocites accumulate at the periphery of the ventricles, failing to enter the trabeculations (Figure 2G,H). In DT embryos the first branchial arch artery is formed, showing roughly the same diameter as the DA, but the second branchial arch artery is severely reduced or absent from these embryos until their death (Figure 2I,J).

\section{$m D I I 4$ overexpression confers arterial phenotype to all ECs}

The Notchl and Heyl $1^{23}$ genes, which are normally expressed specifically in the arterial endothelium, are expressed in the DT embryos both the DA and the ACV (Figure 3A,B,D,E). The ectopic expression of
Heyl in DT embryos represents activation of Notch signaling in the ACV. The arterial specific endothelial markers EphrinB2 and Connexin 37 are expressed in both the DA and the ACV of DT embryos, confirming the establishment of the arterial cell identity in the venous compartment of the mutant embryos (Figure 3G,H,J,K). Separation of the arterial and venous vascular beds appears to be dependent on the expression of EphrinB2 in arteries and $E p h B 4$, the cognate receptor for EphrinB2, in veins. The venous marker EphB4 is down-regulated in the DT embryos, indicating loss of endothelial venous identity (Figure 3I,L). VEGF receptor Flk1/ $V E G F R 2$ is normally expressed on all ECs; however, its expression was reduced in $\mathrm{mDll} 4$ transgenic mutants (Figure 3C,F).

\section{Endothelial cell migration and intersomitic vessel formation is impaired in $\mathrm{mDIl} 4$ overexpressing embryos}

Enlargement of DA in the $m D l l 4$ overexpressing embryos could result from increased endothelial cell proliferation. To test this hypothesis we analyzed the DT and WT embryos for BrdU incorporation and apoptosis. BrdU incorporation was reduced by $43 \%$ in arterial ECs in the DT embryos, compared with the WT (Figure 4A), while the number of ECs per aortic cross-section was 

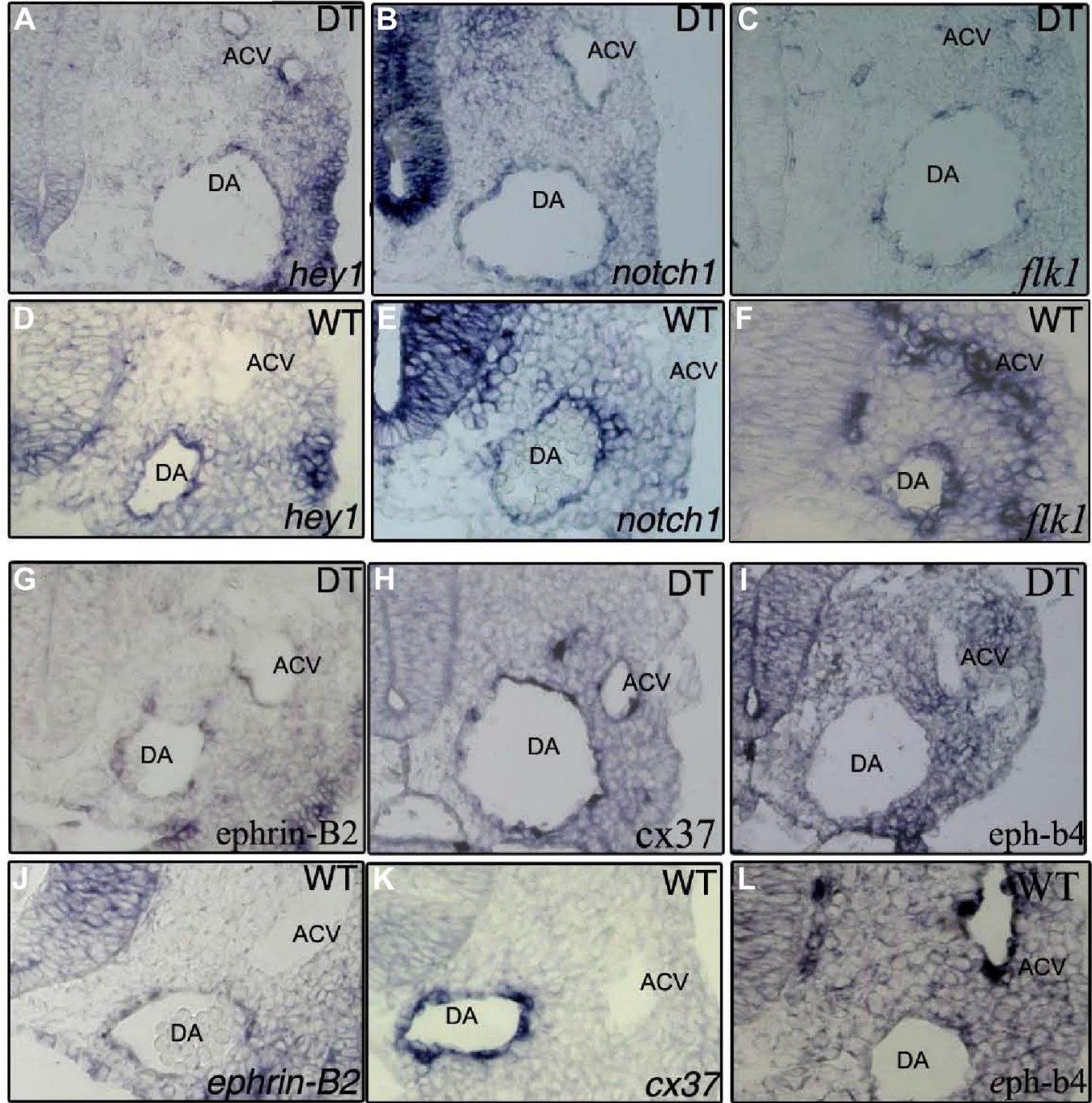

Figure 3. Arterial markers are expressed in all endothelial cells while venous markers are absent in E9.0 DT embryos in situ hybridization. (A,D) hey1 mRNA $(B, E)$ notch1 mRNA. The Notch markers tested show concomitant expression in the aortae (DA) and ACV of DT embryos. Control embryos (D,E) only show expression of these genes in the endothelium of the aortae. (C,F) flk1 mRNA shows lowered expression in the DT embryos. (G,J) ephrin-b2 mRNA, (H,K) connexin37 mRNA. The arterial endothelial specific markers tested show concomitant expression in the aortae and ACV of DT embryos. Control embryos (J,K) only show expression of these genes in the endothelium of the aortae. (I,L) eph-B4 mRNA is not detectable in the ACV of DT embryos despite being detected in the ACV of control embryos (L).

increased by $35 \%$ (Figure 4B). Apoptosis analysis revealed that even though the frequency of apoptotic DT arterial ECs is almost double of that of their WT counterparts, it remains at the relatively low level of $4.7 \%$ (Figure 4C). It appears thus that aortic hypertrophy could be due to a defect in the migration of ECs from the DA to form the intersomitic vessels, as fewer of the intersomitic spaces in the DT embryos were vascularized at E8.5 (Figure 4E) and E9.5 (Figure 4G) as compared with the wild-type (Figure $4 \mathrm{D}, \mathrm{F})$. These results indicate that the ECs are probably migrating dorsally at a slower pace or in reduced numbers, therefore accumulating in the DA and contributing to its enlargement. Furthermore, mutant embryos showed a marked decrease in the branching of the blood vessels. This feature was most prominent in the cephalic region (Figure 4H,I).

\section{$m D I I 4$ overexpression and accumulation of extracellular matrix}

Degradation of the extracellular matrix is a crucial step to the initiation of cell migration. ${ }^{24}$ With the observation of reduced endothelial cell migration, we investigated the possibility of excess matrix deposition or reduced degradation. Fibronectin and, to a lesser extent, laminin, were more abundant around the dorsal aorta of the mutant embryos (Figure 5A-L). We next tested if the increase in matrix proteins was the result of higher expression or reduced degradation. RT-PCR results indicated that there is an increase in expression of fibronectin, laminin and collagen 1 and 4 , and a decrease in the expression of matrix degrading enzymes MMP1, -2, and -9 (Figure 5M). Tissue inhibitors of metalloproteinases (TIMPs) are inhibitors of matrix metalloproteinases (MMPs) ${ }^{25}$ and therefore could be responsible for the decrease in the expression of MMPs. However, the expression levels of TIMP-1, -2 and -3 were not significantly altered in DT embryos (Figure $5 \mathrm{M}$ ).

\section{$m \mathrm{~m} / 14$ overexpression and induction of Notch effectors}

Dl14 mutant embryos reveal arterialization of all vessels defined by the expression of Notch1, Hey1, EphrinB2, and Connexin37. We hypothesized that Dll4 is inducing Notch receptors and its downstream effectors responsible for arterial phenotype. Real-time PCR analysis of putative candidate genes on FACS sorted ECs from WT and DT embryos at 9 to 11 somite stage (Figure $5 \mathrm{~N}$ ) like in situ hybridization data, showed induction of $m D l l 4$ (3.6-fold), and of the Notch effectors, 
From www.bloodjournal.org by on October 21, 2009. For personal use only.

A

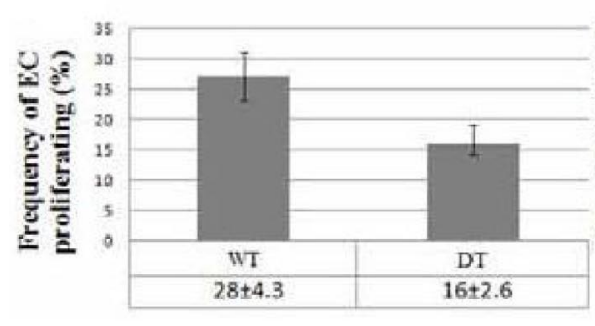

B

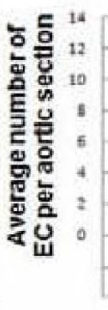

C

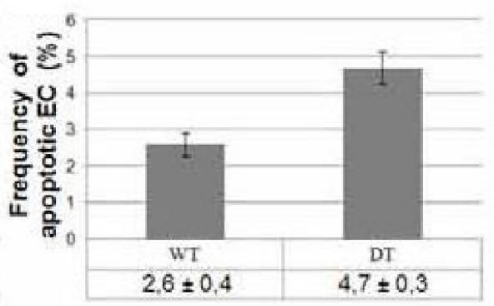

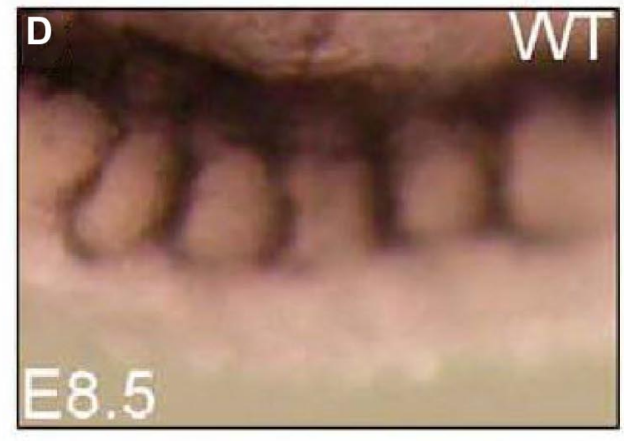
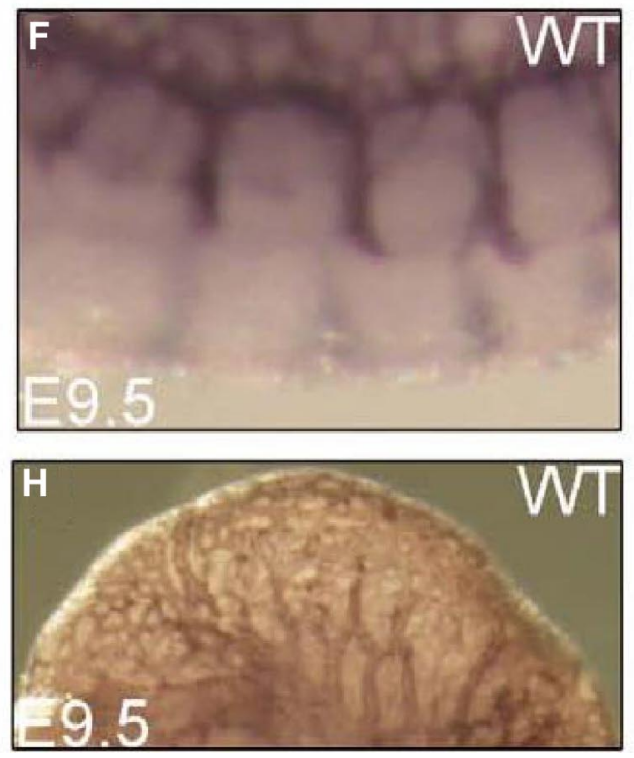
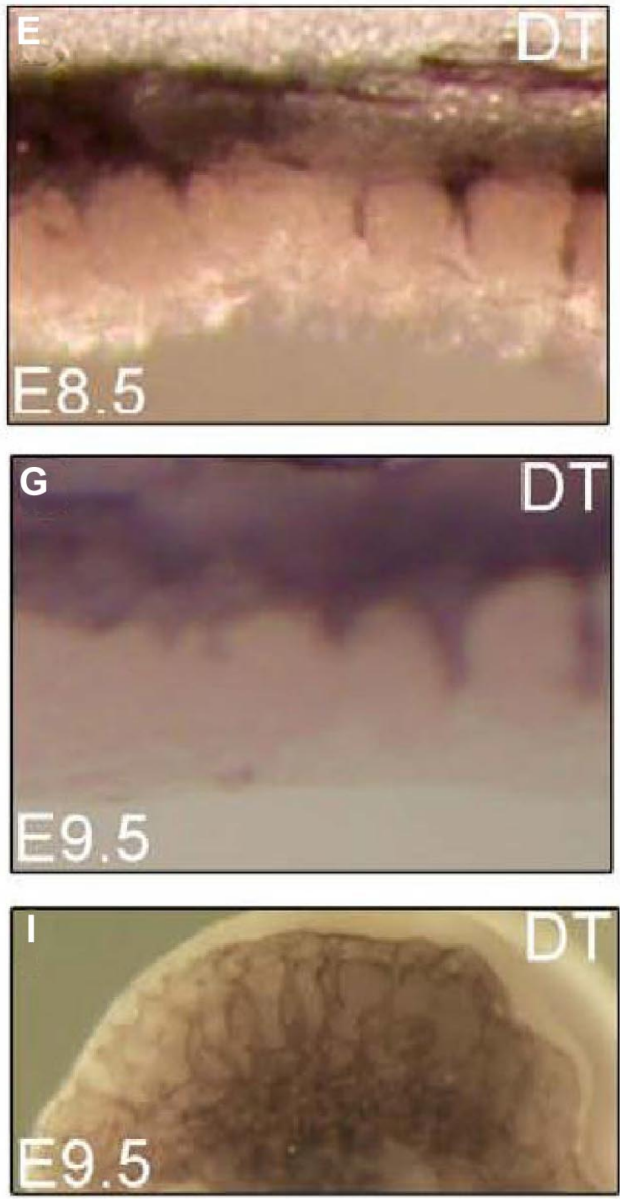

Figure 4. Proliferation of arterial ECs is decreased in DT embryos. (A) BrdU incorporation studies show $16 \%$ of ECs per aortic cross-section of DT embryo are proliferating, compared with $28 \%$ in WT embryos $(P<.01)$. Number of ECs per aortic cross-section is increased in DT embryos. (B) In WT embryos there are on average 8.5 ECs per aortic cross-section, in DT embryos there are $11.5 \mathrm{ECs}$, representing a $35 \%$ increase $(P<.01)$. Apoptosis of arterial ECs is increased in DT embryos. (C) In WT embryos, on average, $2.6 \%$ of arterial ECs are apoptotic, in DT embryos, on average, that frequency is $4.7 \%$, representing a $80 \%$ increase in arterial endothelial apoptosis frequency $(P<.01)$. Endothelial cell migration is delayed in DT embryos. Wholemount PECAM1 immunostaining of E8.5 and E9.5 WT and DT embryos. (D) WT embryo at E8.5. (E) DT embryo at E8.5 showing a delay in the migration of ECs from the DA to form the intersomitic blood vessels, relative to control embryo (D). (F) WT embryo at E8.5. (G) DT embryo at E9.5 showing a continued delay in the migration of ECs from the DA to form the intersomitic blood vessels, relative to control embryo (F). Angiogenic sprouting is reduced in DT embryos (H) Cephalic region of WT embryo at E9.5. (I) DT embryo at E9.5 showing a lowered number of new blood vessel sprouts in cephalic region, relative to control embryo.

the hairy/enhancer-of-split homologues Heyl, Hey2, and Hes5 in DT. EphrinB2 was also up-regulated in Dll4 mutant embryos consistent with the in situ hybridization results. Expression of the venous-specific EphB4 receptor was down-regulated nearly 2-fold. The VEGF and Notch pathways appear to regulate each other. Dll4 expression itself is regulated by VEGF signaling, ${ }^{26}$ conversely Dll4 signaling inhibits VEGF function in ECs in vitro. ${ }^{18}$ Endothelial cells sorted from DT embryos were examined by RT-PCR for the expression of various components of VEGF pathway. In particular VEGFR2 (flk1) had a 4-fold reduction, while VEGF R1 (flt1) was found to be up-regulated 7.2-fold (Figure 5N). In addition Neuropillin-2, a coreceptor for VEGF, was also down-regulated in response to $\mathrm{mDll4}$ over-expression, thus contributing to a reduction of VEGF signaling. VEGF-A expression levels were measured on whole embryo lysates and found to be not significantly altered in the DT embryos. The significance of increased expression (2.9-fold) of VE-cadherin (Figure 5N), a cell-to-cell homophilic adhesion molecule ${ }^{27}$ may also contribute to the mutant phenotype. Endothelial cell guidance, as well as neuronal cell guidance, is a genetically regulated process, under control of several signaling systems. Among these there are several key genes known as regulators of intersomitic blood vessel formation and guidance, such as Robo4, Unc5b, and PlexinD1. ${ }^{28,29}$ In DT embryos Robo4 expression was down-regulated nearly 2 -fold (Figure $5 \mathrm{~N}$ ). Unc $5 \mathrm{~b}$ is a cognate receptor for Netrin1, which acts as a inhibitor of vessel branching. ${ }^{30}$ In DT 

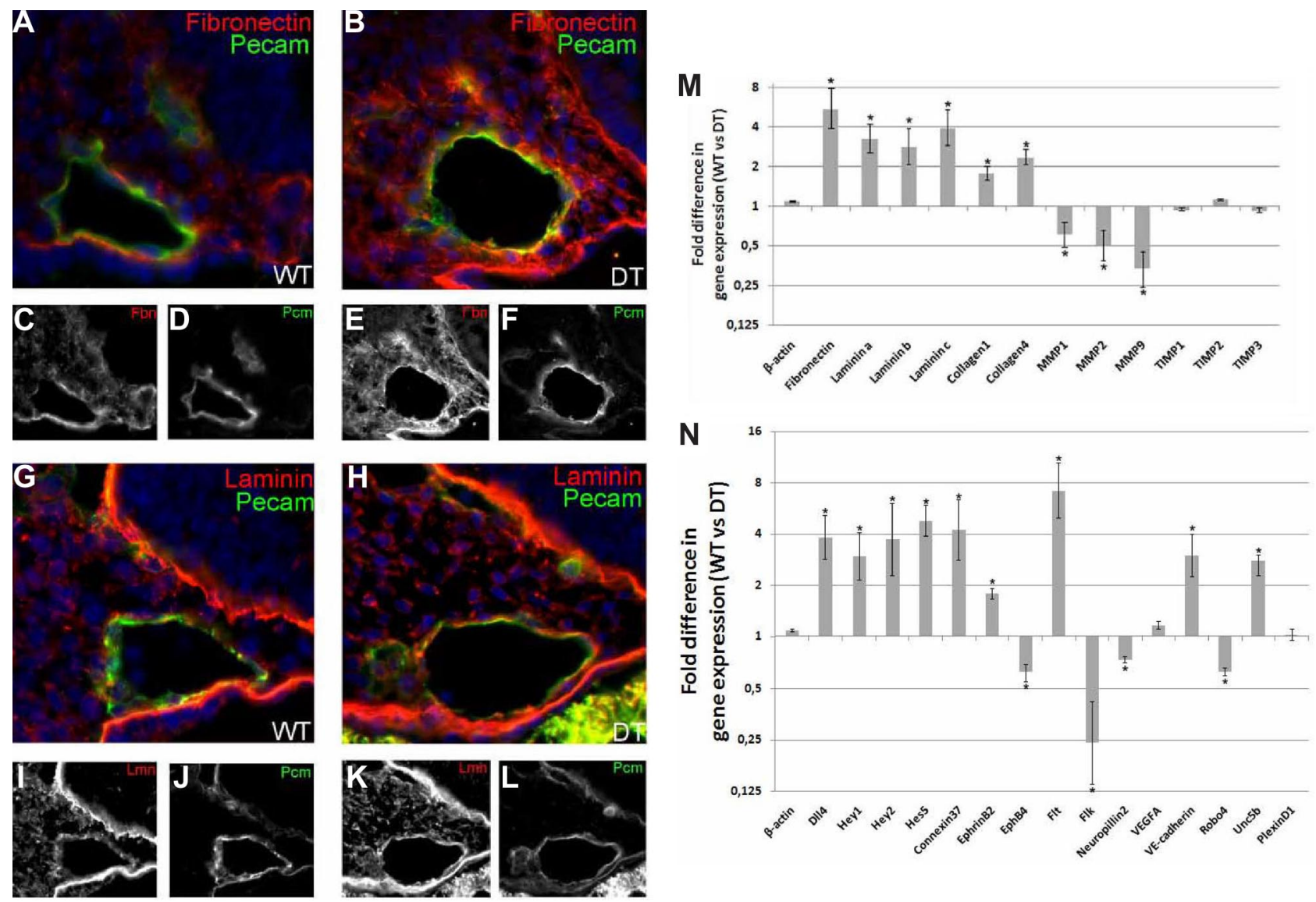

Figure 5. Extracellular matrix deposition around the dorsal aortae is increased in $\mathbf{m D I I 4}$ overexpressing embryos: Immunofluorescence of cryosections from E8.5 DT and control embryos. (A,C,D) Fibronectin deposition around the dorsal aorta of a WT embryo. (B,E,F) DT embryo section showing increased amount of fibronectin surrounding the dorsal aorta, relative to control embryo. (G,I,J) Laminin deposition around the dorsal aorta of a WT embryo. (H,K,L) DT embryo section showing increased deposition of laminin surrounding the dorsal aorta, forming a more defined layer relative to the patchier deposition seen in the control embryo. Matrix protein coding genes expression is increased in mDII4 overexpressing embryos while matrix degrading enzymes coding genes are down-regulated. (M) RT-PCR results for Fibronectin, Laminin, Collagen-1, -4, MMP1, 2, 9 and TIMP1, 2, and 3 compared with WT and DT ECs. (N) Transcriptional analysis of mDIl4 overexpressing embryonic ECs. Notch pathway genes (Hey1, Hey2, Hes5), arterial markers (Connexin37, EphrinB2), and cell-to-cell adhesion protein coding genes (VE-cadherin) are up-regulated as a consequence of DII4 overexpression. Venous marker (EphB4) and VEGF receptors Flk1 and Neuropillin2 are down-regulated while Flt is up-regulated. VEGF-A expression, measured from whole embryo lysates, is not significantly altered in DT embryos. Robo4 is down-regulated, Unc5b is up-regulated and PlexinD1 is not significantly altered. Relative quantitative gene expression in DT embryos compared with WT ( $\mathrm{n}=3$ per group). Values were normalized in relation to $\beta$-actin expression. ${ }^{\star} P<.01$

embryos Unc5b expression was up-regulated 2.8-fold (Figure 5N). PlexinD1 is a semaphorin receptor normally expressed by intersomitic vessels. ${ }^{28}$ It is also involved in mediating guidance of new intersomitic vessels. ${ }^{19}$ In DT embryos, PlexinD1 expression was not significantly altered from the WT embryos (Figure 5N).

\section{DII4 inhibited endothelial cell migration and tube formation}

We intended to determine whether full-length Dll4 could mimic the $m D l l 4$ embryonic gain-of-function phenotype. HUVECs transiently transfected with a full-length Dll4 expression vector, or vector alone, were sorted and studied for various functions including migration and tube formation.

Confluent ECs were wounded by a single scrape with a sterile plastic Pasteur pipette. Migration of cells into the cleared zone was evaluated and quantified over 18 hours. Dll4-FL expressing cells migrate poorly even in the presence of exogenous VEGF when compared with vector only transfected cells. However the addition of soluble form of Dll4 reversed the effect of Dll4-Fl leading to increased cell migration into the cell clear zone (Figure 6A,B).

Dl14-FL or vector transfected ECs were tested in tube formation assays using ECs placed on polymerized Matrigel to promote the formation of tube like structures. Minimal amounts of tubes were formed in the absence of growth factors, and abundant tube formation was observed with the addition of VEGF. Dll4-FL showed a reduction of tube formation even in the presence of exogenous VEGF (Figure 6C). Soluble form of Dll4 nearly completely abolished the inhibitory effect of Dll4-FL (Figure 6C). Dll4-FL however had no significant effect on cell proliferation or apoptosis (Figure 6C).

Dl14-FL or vector only expressing ECs were examined for expression of selected genes. DLL4 was induced in cells transfected with Dll4-FL expression vector (Figure 6E). In addition, genes known to be regulated by Dll4-Notch indeed showed the expected pattern of regulation, such as down-regulation of EphB4 and up-regulation of EphrinB2, Notch4, Heyl, and Hey2. In addition, a pronounced induction of Fibronectin and reduction of VEGFR2 was noted, in concordance with the results obtained in ECs from DT embryos (Figure 6E).

\section{DII4 reduced vascularization and increased pericyte recruitment of Matrigel plugs in vivo}

To further demonstrate that Dll4 can directly modulate angiogenesis in vivo, we performed a murine Matrigel plug experiment. Matrigel was 
Time $=18 \mathrm{~h}$
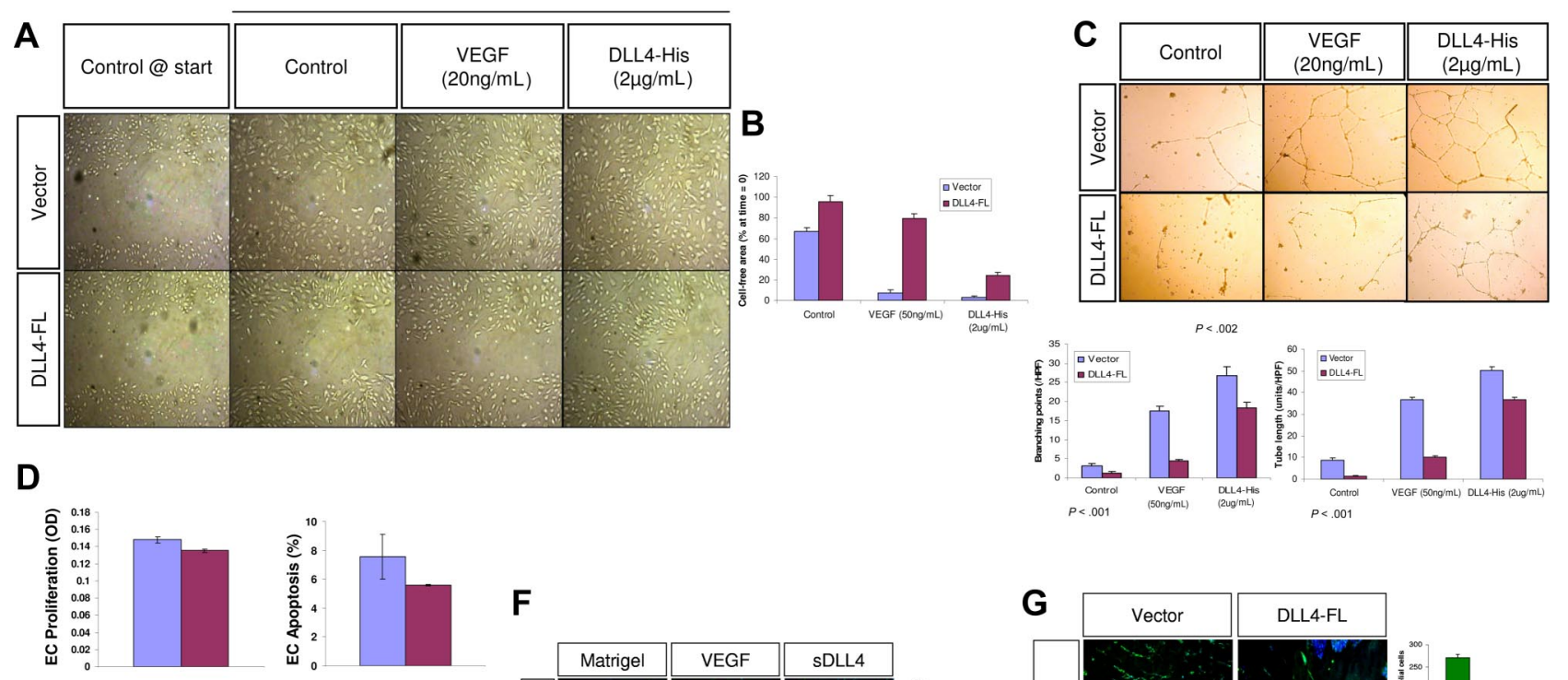

$\mathbf{F}$

E

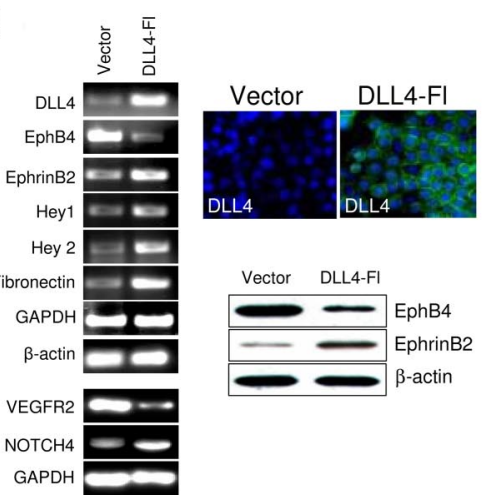

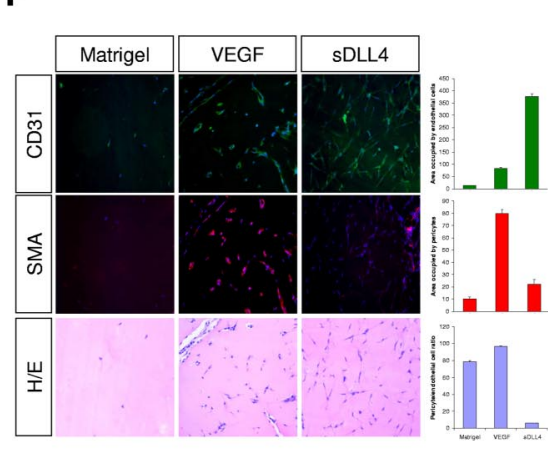

G

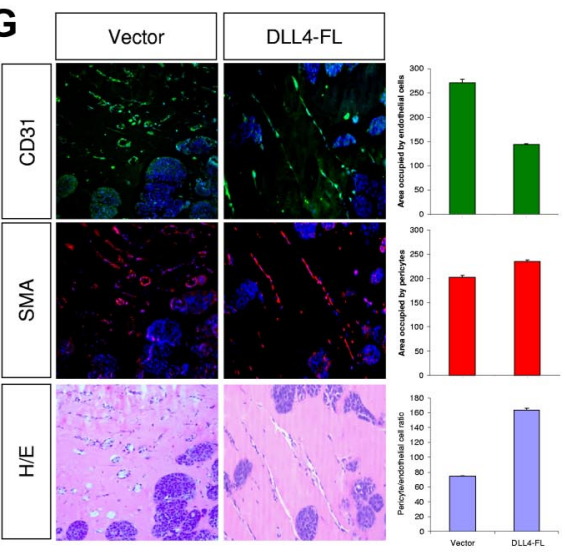

Figure 6. DII4-FL inhibits EC migration. (A) HUVECs were transfected with expression vectors for DII4-FI or vector alone and sorted for transfected cells. Confluent cultures of HUVECs were scraped with a plastic Pasteur pipette to produce a 3-mm-wide cell-free zone in the monolayer. The ability of the cells to migrate and close the wound was assessed over 18 hours. DII4-FI inhibited the migration of ECs even in the presence of VEGF, while exogenous sDII4 abolished this inhibition. (B) Endothelial cell migration into the cell free zone was quantitated using Bioquant Image Analysis (mean \pm SEM from triplicate wells in 2 repetition experiments). ${ }^{*} P<.05$ when DII4-FI is compared with vector alone treated either with VEGF or sDll4-His. DII4-FI inhibits tubule formation in vitro. Photomicrographs were taken with a Nikon Plan Fluor, $0.17,4 \times / 0.12$ NA objective and 10× eyepiece and processed with Image-Pro Plus 6.0 (Media Cybernetics, Bethesda, MD). (C) HUVECs were transfected with expression vectors for DII4-FI or vector alone and sorted cells were cultured on standard Matrigel in growth factor-deficient conditions in triplicates in 2 independent experiments with either sDII4 or VEGF for 18 hours. Shown are representative pictures from triplicate wells repeated twice. Quantitative analysis for tube length and the number of junctions in various groups is presented. ${ }^{\star} P<.05$ compared with no growth factor. (D) HUVECs transfected with DII4-FI or vector alone were evaluated for cell proliferation (left panel) after 72 hours. Apoptosis in serum-deprived conditions was measured after 24 hours, using annexin-V FITC (right panel). DII4-FI induces fibronectin and artery specific genes. (E) HUVECs were transfected with expression vectors for DII4-FI or vector alone and sorted for transfected cells. DII4 expression in DII4-FI transfected and sorted cells was assessed using MabDII4-FITC. cDNA was analyzed by RT-PCR for the expression of various genes that are differentially regulated in venous and arterial ECs. GAPDH and $\beta$-actin expression was examined to document equal amount of cDNA in each group. Two independent experiments produced similar results. EphB4, EphrinB2 and $\beta$-actin protein levels were evaluated by immunoblotting (bottom right panel). sDll4 induces vessel response in murine Matrigel assay. (F) Matrigel lacking growth factor or impregnated with VEGF or VEGF + sDII4-His were injected subcutaneously into Balb/C nu/nu mice. After 6 days, plugs were removed and processed in paraffin. Individual sections were stained with $\mathrm{H} \& \mathrm{E}$, and representative photographs at $20 \times$ magnification from triplicate plugs in 2 independent experiments are shown. Matrigel plugs were stained for PECAM/CD31, or SMA. Photomicrographs were taken with an Olympus BX51 microscope with an Olympus UPlan FL, $0.1720 \times / 0.5$ NA dry objective mounted with a Retiga $2000 R$ camera (QImaging, Burnaby, BC) and processed with Image-Pro Plus 6.0 (Media Cybernetics). Quantitation of CD31, SMA positive cells was as in Figure 3. (G) DII4-Fl induces fewer vessels with increased SMA. 293T cells were transfected with expression vectors for DII4-FI or vector alone and sorted cells were implanted in standard Matrigel in growth factor-deficient conditions in triplicates in 2 independent experiments. After 6 days, plugs were removed and processed in paraffin. Individual sections were stained with $\mathrm{H} \& \mathrm{E}$, and representative photographs at $20 \times$ magnification from triplicate plugs in 2 independent experiments are shown. Matrigel plugs were stained for PECAM/CD31, or SMA. Photomicrographs were taken with an Olympus BX51 microscope with an Olympus UPlan FL, $0.1720 \times / 0.5$ NA dry objective mounted with a Retiga 2000R camera (QImaging) and processed with Image-Pro Plus 6.0 (Media Cybernetics). Quantitation of CD31, SMA-positive cells was as in Figure 3.

impregnated with VEGF and either 293T cell line-expressing fulllength Dll4-Fl, or vector alone. The matrigel-cell admixture was injected into the ventral abdominal subcutaneous tissue of Balb/C nu/nu mice. Matrigel plugs were harvested on day 6 and examined for vascular density with PECAM/CD31 and pericytes with smooth muscle actin localization (Figure 6F). VEGF containing plugs formed various stages of vascular structures (6.5-fold more vessels compared with Matrigel alone) including those with open lumen, and encased with pericytes. Soluble Dll4 containing plugs formed more vascular structures (4.6-fold increase compared with VEGF alone), but these vessels had no appreciable lumen. In addition, whereas almost all VEGF-induced vessels had recruited pericytes, only $22 \%$ vessels contained pericytes in the presence of sDLL4 (Figure 6A). In sharp contrast, Matrigel plugs containing 293T cells transfected with Dll4-FL had 53\% fewer blood vessels compared with vector alone, had rare branch points, and contained large lumen. Furthermore, there was a 2.2-fold increase in pericytes recruited to blood vessels in the presence of Dll4-FL compared with vector alone (Figure 6G). 


\section{Discussion}

Dll4 is the only known Notch ligand expressed on arterial endothelium, in complementary fashion to Notch1 and Notch4. Loss-of-function studies revealed that Dll4 is the ligand responsible for Notch signaling activation in the developing vasculature of mice, leading to reduced and collapsed DA, angiogenic remodeling defects, and loss of arterial endothelial identity in a dosage-sensitive manner. ${ }^{10}$ To further the understanding of Dll4 function in vascular development we produced conditional overexpression transgenics.

Dll4 overexpression in the transgenic embryos led to arterialization of the venous endothelium. In the mutant embryos, arterial specific markers, including Ephrin-B2, are also expressed in veins. The resulting vascular system showed premature fusion between arteries and veins possibly from the loss of repulsive signal between arterial and venous vascular bed. This phenotypic feature has also been seen in Dll4, ${ }^{10}$ Endoglin, and $A L K 1^{31}$ knockout mutants.

The presence of arterio-venous malformations produces a circulatory defect by blood flowing out of the heart through the DA and back directly into the heart through the sinus venosus, thus reducing perfusion, contributing to the mutant phenotype.

Overexpression of Dll4 also displays heart defects. The ventricles of DT embryos show reduced trabeculation, with reduced cardiomyocites in the inner layers of the trabeculae relative to the ventricular wall. The atria also showed a marked dilation. The outflow tract showed reduced cells within its cushions and absence of the second branchial arch arteries. As the vascular defects precede the initiation of the heartbeat, it is possible that some of the defects are independent of defective blood flow. ${ }^{10}$

Analysis of proliferation rates of arterial ECs showed that there is approximately a $50 \%$ decrease in proliferation rate of arterial ECs with, on average, a $35 \%$ increase in the number of ECs per aortic crosssection. The increased number of ECs explains the hyperplasia of the DA in these embryos, which appears in contradiction to the observed decrease in the proliferation rate of these cells. Endothelial apoptosis is doubled on DT embryos, accounting for $4.7 \%$ of arterial ECs, again contradicting the increase in the number of aortic ECs. The other possibility for explaining the increase in the number of aortic ECs is decreased endothelial migration. Endothelial cell migration into the intersomitic spaces to form the intersomitic vessels is dependent on attractive signals created by proangiogenic factors such as VEGF, which are secreted by dorsal structures like the somites and the neural tube. ${ }^{32,33}$ In situ hybridization and RT-PCR results show that the mutant embryos have marked reduction in VEGFR2 expression. It is likely that the migration delay observed in the formation of the intersomitic vessels of DT embryos is due in part to decreased sensitivity to VEGF signaling. Altered expression of Robo4 and Unc5b may also contribute to the mutant phenotype. ${ }^{28-30}$ A decrease in the branching of cranial blood vessels was also observed. Dll4-Notch pathway thus regulates vascular sprouts. ${ }^{34-36}$

The basal lamina needs to be dissolved before an endothelial cell can initiate migration. We observed an increase in fibronectin deposition around the DA and a slight increase in laminin deposition, which may account for a more compacted basal lamina around the DA endothelium, and reduced endothelial cell migration. RT-PCR results also indicate an increase in the expression of Collagen 1 and 4, and reduced expression of matrix proteinases, MMP-1,-2, and 9. These findings were supported by 2 independent methods, immunofluorescence and RT-PCR, both in vivo in the transgenic embryos and in vitro in Dll4-FL transfected ECs. Transcriptional analysis by RT-PCR shows that Dll4 regulates VEGF signaling by up-regulating VEGF-R1 and down-regulating VEGF-R2. ${ }^{37}$ VEGF-R1 seems to act as a VEGF sink during embryonic vascular development, both at the membrane and also as a soluble form. ${ }^{38,39}$ Down-regulation of Neuropillin-2, a coreceptor for VEGF may also contribute to the reduction in VEGF function. ${ }^{40}$

Given the failure to obtain endothelial specific overexpression with the ZEG-D114 conditional transgenics, the subsequent production of tet $\mathrm{O}_{7}$-Dll4 mouse lines allowed us to ascertain whether the defects observed in the DT embryos were indeed only derived from homotypic interactions between Dll4 overexpressing ECs or some form of secondary effect caused by ectopic Dll4 overexpression. As endothelial-specific overexpression of Dll4 produced the same cardiovascular phenotype, with lethality at the same stage in development, we can attribute the cause of the cardiovascular phenotype described in DT embryos to homotypic interactions at the endothelial level.

In vitro work confirmed the results obtained with the transgenic embryos indicating that Dll4-FL inhibits the migratory phenotype induced in ECs by VEGF signaling, which is reminiscent of the delayed growth of the intersomitic vessels of DT embryos. Dll4-FL was also confirmed as being able to inhibit branching angiogenesis and tubulogenesis induced by VEGF, which is similar to what happens in the vasculature of the cephalic region of DT embryo.

Dll4 has recently been shown to be an important modulator of tumor growth. Studies with inhibitors of Dll4 have shown these to produce a tumor vasculature that, while being more abundant, was less mature and had markedly reduced perfusion leading to reduced tumor growth. ${ }^{17,41,42}$ Dll4-FL expressing $293 \mathrm{~T}$ cells, when implanted in Matrigel, produced fewer vessels which displayed greater maturation, including larger lumen and abundant pericytes. It is of importance that this phenotype is the opposite of what is observed in $\mathrm{mDll4}^{-/-}$embryos, where there is increased proliferation with decreased number of EC per aortic cross-sections. In the $\mathrm{mDll}^{-/-}$embryos aortic ECs migrate more in response to VEGF gradients and create more new branches, leaving a severely reduced and collapsed DA (unpublished data). Recent works in zebrafish ${ }^{43,44}$ also confirm this phenotype and the interplay with VEGF in vivo.

In sum, Dll4 appears to work as a negative regulator of angiogenesis, antagonizing VEGF function by negatively regulating VEGF receptor expression. Dll4 negatively regulates endothelial cell proliferation, migration and vessel branching and positively regulates extracellular matrix deposition and endothelial cell-to-cell adhesion. Dll4 is a VEGF responsive gene ${ }^{26}$ and acts as negative regulator of VEGF signaling. This interplay reveals a mechanism whereby ECs make continuous dosage dependent decisions on whether to carry out effective expansion of the vascular network or become quiescent contributing to the maturation of the blood vessels, a critical balance in the formation and remodeling of the vascular system.

\section{Acknowledgments}

The authors are indebted to Drs Corrine Lobe and J. A. Whitsett for the gift of transgenic vectors and to Dr Urban Deutsch for the gift of cre transgenic mouse lines.

This work was supported by NCI-RO1 CA 079218-07 (P.S.G.), Women's Cancer Research Fund, Mesothelioma Foundation of America, Fundação para a Ciência e Tecnologia (FCT, Portugal) grants POCTI/CVT/48 766/2002 and POCTI/CVT/56 015/2004 (A.D.). A.T. is the recipient of a FCT PhD studentship. 


\section{Authorship}

Contribution: A.T., P.S.G., and A.D. designed the studies and wrote the manuscript; and A.T., S.R.K., J.S.S., L.L.-C., J.B., W.J., R.L., P.S.G., and A.D. performed research and analyzed data.
Conflict-of-interest disclosure: W.J. and R.L. are employees of VasGene Therapeutics. All other authors declare no competing financial interests.

Correspondence: Parkash S. Gill, MD, Norris Cancer Center, Room 6332, 1441 Eastlake Avenue, Los Angeles, CA 90033; e-mail: parkashg@usc.edu.

\section{References}

1. Wang HU, Chen ZF, Anderson DJ. Molecular distinction and angiogenic interaction between embryonic arteries and veins revealed by ephrin-B2 and its receptor Eph-B4. Cell. 1998;93:741-753.

2. Gerety SS, Wang HU, Chen ZF, Anderson DJ. Symmetrical mutant phenotypes of the receptor EphB4 and its specific transmembrane ligand ephrin-B2 in cardiovascular development. Mol Cell. 1999;4:403-414

3. Adams RH, Wilkinson GA, Weiss C, et al. Roles of ephrinB ligands and EphB receptors in cardiovascular development: demarcation of arterial/ venous domains, vascular morphogenesis, and sprouting angiogenesis. Genes Dev. 1999;13: 295-306.

4. Gale NW, Baluk P, Pan L, et al. Ephrin-B2 selectively marks arterial vessels and neovascularization sites in the adult, with expression in both endothelial and smooth-muscle cells. Dev Biol. 2001;230:151-160.

5. Krebs LT, Xue Y, Norton CR, et al. Notch signaling is essential for vascular morphogenesis in mice. Genes Dev. 2000;14:1343-1352.

6. Uyttendaele H, Marazzi G, Wu G, Yan Q, Sassoon D, Kitajewski J. Notch4/int-3, a mammary proto-oncogene, is an endothelial cellspecific mammalian Notch gene. Development. 1996;122:2251-2259.

7. Shutter JR, Scully S, Fan W, et al. DII4, a novel Notch ligand expressed in arterial endothelium. Genes Dev. 2000;14:1313-1318.

8. Lawson ND, Vogel AM, Weinstein BM. sonic hedgehog and vascular endothelial growth factor act upstream of the Notch pathway during arteria endothelial differentiation. Dev Cell. 2002;3:127136.

9. Fischer A, Schumacher N, Maier M, Sendtner M Gessler M. The Notch target genes Hey1 and Hey2 are required for embryonic vascular development. Genes Dev. 2004;18:901-911.

10. Duarte A, Hirashima M, Benedito R, et al. Dosage-sensitive requirement for mouse DII4 in artery development. Genes Dev. 2004;18:24742478 .

11. Sakai K, Miyazaki J. A transgenic mouse line that retains Cre recombinase activity in mature oocytes irrespective of the cre transgene transmission. Biochem Biophys Res Commun. 1997;237: 318-324.

12. Novak A, Guo C, Yang W, Nagy A, Lobe CG Z/EG, a double reporter mouse line that expresses enhanced green fluorescent protein upon Cre-mediated excision. Genesis. 2000;28: 147-155.

13. Hogan B, Beddington R, Constantini F, Lacy E. Manipulating the mouse embryo. A laboratory manual (2nd ed). Woodbury, NY: Cold Spring Harbor Laboratory Press; 1994.

14. Akeson AL, Greenberg JM, Cameron JE, et al. Temporal and spatial regulation of VEGF-A controls vascular patterning in the embryonic lung. Dev Biol. 2003;264:443-455.
15. Henrique D, Hirsinger E, Adam J, et al. Maintenance of neuroepithelial progenitor cells by DeltaNotch signalling in the embryonic chick retina. Curr Biol. 1997;7:661-670.

16. Dunwoodie SL, Henrique D, Harrison SM, Beddington RS. Mouse DII3: a novel divergent Delta gene which may complement the function of other Delta homologues during early pattern formation in the mouse embryo. Development. 1997; 124:3065-3076.

17. Scehnet JS, Jiang W, Kumar SR, et al. Inhibition of DII4 mediated signaling induces proliferation of immature vessels and results in poor tissue perfusion. Blood. 2007;109:4753-4760.

18. Williams CK, Li JL, Murga M, Harris AL, Tosato G. Up-regulation of the Notch ligand Delta-like 4 inhibits VEGF-induced endothelial cell function. Blood. 2006;107:931-939.

19. Gu C, Yoshida Y, Livet J, et al. Semaphorin $3 E$ and plexin-D1 control vascular pattern independently of neuropilins. Science. 2005;307:265-268.

20. Kisanuki YY, Hammer RE, Miyazaki J, Williams SC, Richardson JA, Yanagisawa M. Tie2-Cre transgenic mice: a new model for endothelial celllineage analysis in vivo. Dev Biol. 2001;230:230242.

21. Gustafsson E, Brakebusch C, Hietanen K, Fassler R. Tie-1-directed expression of Cre recombinase in endothelial cells of embryoid bodies and transgenic mice. J Cell Sci. 2001;114:671676.

22. Motoike T, Markham DW, Rossant J, Sato TN. Evidence for novel fate of Flk1+ progenitor: Contribution to muscle lineage. Genesis. 2003;35: 153-159.

23. Steidl C, Leimeister C, Klamt B, et al. Characterization of the human and mouse HEY1, HEY2, and $H E Y L$ genes: cloning, mapping, and mutation screening of a new bHLH gene family. Genomics. 2000;66:195-203.

24. Conway EM, Collen D, Carmeliet P. Molecular mechanisms of blood vessel growth. Cardiovasc Res. 2001;49:507-521.

25. Brew K, Dinakarpandian D, Nagase H. Tissue inhibitors of metalloproteinases: evolution, structure and function. Biochim Biophys Acta. 2000 1477:267-283.

26. Liu ZJ, Shirakawa T, Li Y, et al. Regulation of Notch1 and DII4 by vascular endothelial growth factor in arterial endothelial cells: implications for modulating arteriogenesis and angiogenesis. Mo Cell Biol. 2003;23:14-25.

27. Gory-Faure S, Prandini MH, Pointu H, et al. Role of vascular endothelial-cadherin in vascular morphogenesis. Development. 1999;126:2093-2102.

28. Suchting S, Bicknell R, Eichmann A. Neuronal clues to vascular guidance. Exp Cell Res. 2006; 312:668-675.

29. Bedell VM, Yeo SY, Park KW, et al. roundabout4 is essential for angiogenesis in vivo. Proc Natl Acad Sci U S A. 2005;102:6373-6378.
30. Lu X, Le Noble F, Yuan L, et al. The netrin receptor UNC5B mediates guidance events controlling morphogenesis of the vascular system. Nature. 2004;432:179-186.

31. Sorensen LK, Brooke BS, Li DY, Urness LD. Loss of distinct arterial and venous boundaries in mice lacking endoglin, a vascular-specific TGFbeta coreceptor. Dev Biol. 2003;261:235-250.

32. Coultas L, Chawengsaksophak K, Rossant J. Endothelial cells and VEGF in vascular development. Nature. 2005:438:937-945.

33. Rossant J, Hirashima M. Vascular development and patterning: making the right choices. Curr Opin Genet Dev. 2003;13:408-412.

34. Hellstrom M, Phng LK, Hofmann JJ, et al. DII4 signalling through Notch1 regulates formation of tip cells during angiogenesis. Nature. 2007;445: 776-780.

35. Lobov IB, Renard RA, Papadopoulos N, et al. Delta-like ligand 4 (DII4) is induced by VEGF as a negative regulator of angiogenic sprouting. Proc Natl Acad Sci U S A. 2007:104:3219-3224.

36. Suchting S, Freitas C, le Noble F, et al. The Notch ligand Delta-like 4 negatively regulates endothelial tip cell formation and vessel branching. Proc Natl Acad Sci U S A. 2007;104:3225-3230.

37. Veikkola T, Karkkainen M, Claesson-Welsh L, Alitalo K. Regulation of angiogenesis via vascular endothelial growth factor receptors. Cancer Res. 2000;60:203-212.

38. Hiratsuka S, Minowa O, Kuno J, Noda T, Shibuya M. Flt-1 lacking the tyrosine kinase domain is sufficient for normal development and angiogenesis in mice. Proc Natl Acad Sci U S A. 1998;95:93499354.

39. Hiratsuka S, Nakao K, Nakamura K, Katsuki M, Maru Y, Shibuya M. Membrane fixation of vascular endothelial growth factor receptor 1 ligandbinding domain is important for vasculogenesis and angiogenesis in mice. Mol Cell Biol. 2005;25: 346-354.

40. Soker S, Takashima S, Miao HQ, Neufeld G, Klagsbrun M. Neuropilin-1 is expressed by endothelial and tumor cells as an isoform-specific receptor for vascular endothelial growth factor. Cell. 1998;92:735-745

41. Noguera-Troise I, Daly C, Papadopoulos NJ, et al. Blockade of Dll4 inhibits tumour growth by promoting non-productive angiogenesis. Nature. 2006;444:1032-1037.

42. Ridgway J, Zhang G, Wu Y, et al. Inhibition of DIl4 signalling inhibits tumour growth by deregulating angiogenesis. Nature. 2006;444:1083-1087.

43. Leslie JD, Ariza-McNaughton L, Bermange AL, McAdow R, Johnson SL, Lewis J. Endothelial signalling by the Notch ligand Delta-like 4 restricts angiogenesis. Development. 2007;134:839-844.

44. Siekmann AF, Lawson ND. Notch signalling limits angiogenic cell behaviour in developing zebrafish arteries. Nature. 2007;445:781-784 